\title{
From Ribbons to Networks: Hierarchical Organization of DNA- grafted Supramolecular Polymers
}

\author{
Yuliia Vyborna, Mykhailo Vybornyi and Robert Häner* \\ Department of Chemistry and Biochemistry, University of Bern, Freiestrasse3, CH-3012 Bern Switzerland \\ Supporting Information Placeholder
}

\begin{abstract}
DNA-grafted supramolecular polymers (SPs) allow the programmed organization of DNA in a highly regular, one-dimensional array. Oligonucleotides are arranged along the edges of pyrene-based helical polymers. Addition of complementary oligonucleotides triggers the assembly of individual nanoribbons resulting in the formation of extended supramolecular networks. Network formation is enabled by cooperative coaxial stacking interactions of terminal GC base pairs. The process is accompanied by structural changes in the pyrene polymer core that can be followed spectroscopically. Network formation is reversible and disassembly into individual ribbons is realized either via thermal denaturation or by addition of a DNA separator strand.
\end{abstract}

The creation of functional nanoscale structures represents a major goal of today's nanotechnology. DNA-based materials are of primary interest for the construction of functional platforms. ${ }^{1-4}$ Proper choice of the nucleotide sequence provides control over aromatic stacking and hydrogen bonding interactions, ${ }^{5-7}$ thus enabling the assembly of systems with a high degree of complexity. ${ }^{8-11}$ Approaches towards the preparation of functional DNA materials include the designed DNA self-assembly, ${ }^{12-15}$ the grafting of oligonucleotides onto metal nanoparticles (NPs) ${ }^{16}$ and other surfaces, ${ }^{17-19}$ as well as polymers. ${ }^{20-23}$ The latter class, DNA-grafted polymers, has been pioneered by Nguyen and Mirkin and gained increasing attention over the last years. ${ }^{24,25}$ We have recently introduced DNA-grafted supramolecular polymers (SPs). ${ }^{26}$ These self-assembled structures appear as one-dimensional (1D) ribbons, consisting of an oligopyrenotide cor ${ }^{27}$ with arrays of singlestranded oligonucleotides appended onto its edges. The non-covalent nature of SPs brings the additional feature of reversibility of the polymerization process. ${ }^{28-34}$ Furthermore, it enables the formation of polymers with a high DNA grafting density. ${ }^{25,26}$ Herein we describe the hierarchical organization of DNA-grafted SPs. It is shown that individual ribbons assemble into extended networks through a highly cooperative mesh of DNA blunt end stacking interactions.

Chimeric oligomers Py-a, Py-b and Py-c (Scheme 1) are all composed of a heptapyrenotide part and an appended oligonucleotide. They were prepared via solid-phase synthesis, purified by RP-HPLC and characterized by MS (SI). The two complementary oligonucleotides $1 \mathbf{a}$ (separator strand) and $\mathbf{1 b}$ (connector strand) have the same nucleobase sequence as the respective corresponding chimeric oligomers Py-a and Py-b; 1c is complementary to the oligonucleotide part of Py-c.

\author{
$(\text { Py })_{7}$ - CTTCCGTGAG-3' \\ Py-a \\ $(\text { Py })_{7}$ - CTCACGGAAG-3' \\ Py-b \\ $\left(\right.$ Py $_{7}-$ CTTCCGTGGA-3'
Py-c \\ CTTCCGTGAG-3' \\ la (separator strand) \\ CTCACGGAAG-3' \\ $\mathbf{l b}$ (connector strand) \\ TCCACGGAAG-3'
}

lc
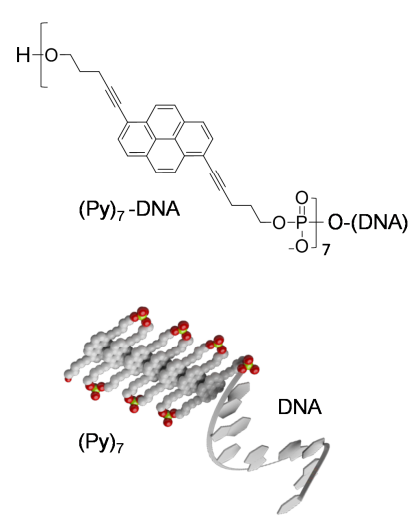

Scheme 1. Left: Sequences of chimeric oligomers and oligonucleotides; top right: chemical structure of phosphodiester-linked pyrene part; bottom right: illustrative representation of chimeric oligomers.
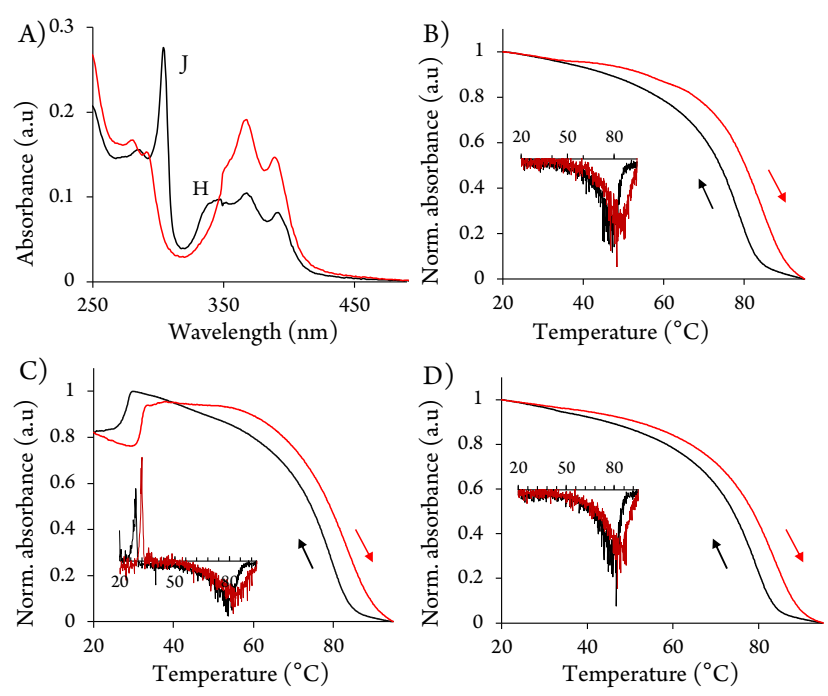

Figure 1. A) UV/vis of Py-a at $20^{\circ} \mathrm{C}$ (black) and $95^{\circ} \mathrm{C}$ (red). Temperature-dependent change of absorbance at $305 \mathrm{~nm}$ of Py-a (B), Py-a* $1 \mathrm{~b}$ (C) and Py-a $+1 \mathrm{a}(\mathrm{D})$. Arrows indicate cooling and heating. Cooling (black) and heating (red) were performed using a $0.1{ }^{\circ} \mathrm{C} / \mathrm{min}$ ramp. Conditions: $2 \mu \mathrm{M}$ Py-a and $6 \mu \mathrm{M}$ of $1 \mathrm{~b}(\mathrm{C})$ or $1 \mathrm{a}(\mathrm{D})$; $10 \mathrm{mM}$ phosphate buffer, $\mathrm{pH}=7.0,250 \mathrm{mM}$ sodium chloride. The insets in (B)-(D) show the first derivatives of the corresponding curves. The full width at half-maximum 


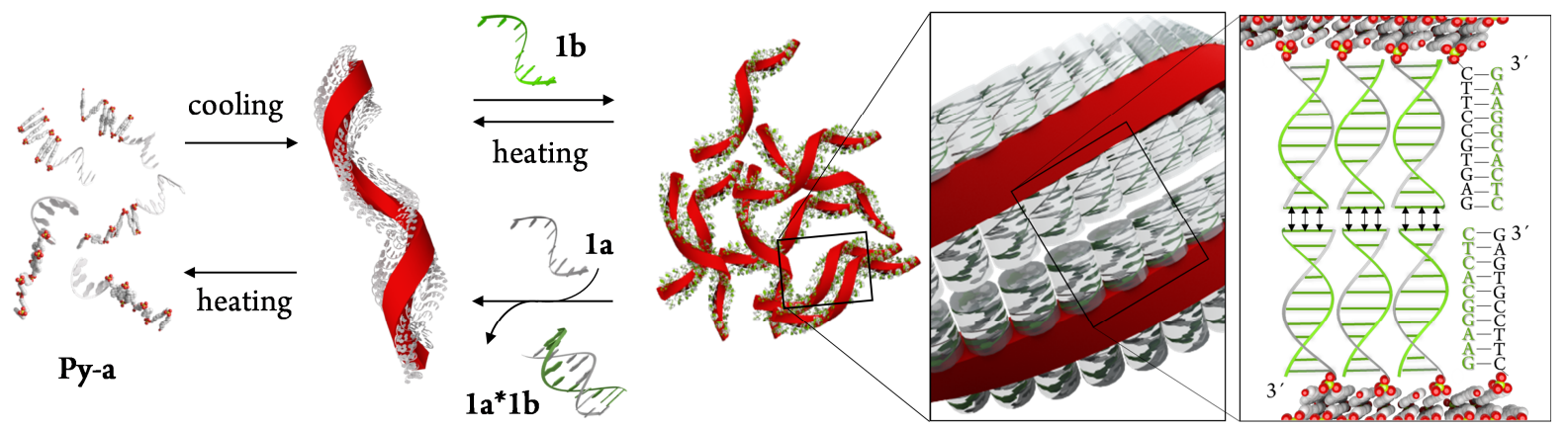

Scheme 2. Illustration of hierarchical self-assembly process. Nanoribbons are formed through assembly of chimeric oligomers (Py-a) in a first step. Subsequent hybridization of oligonucleotide $\mathbf{1 b}$ to the DNA part of the nanoribbons leads to formation of duplexes containing GC base pairs at their ends. Networks are then formed via cooperative blunt end stacking interactions.

DNA-grafted SPs are typically performed by slow annealing. Thus, a $2 \mu \mathrm{M}$ solution of Py-a in aqueous buffer ( $10 \mathrm{mM}$ sodium phosphate, $\mathrm{pH}=7.0$ and $250 \mathrm{mM}$ sodium chloride) is cooled from $95^{\circ}$ to $20^{\circ} \mathrm{C}$ using a gradient of $0.1^{\circ} \mathrm{C} / \mathrm{min}$. Stacking interactions between pyrenes drive the self-assembly of polymeric ribbons. The polymerization process leads to the development of two distinct absorption bands in the $\mathrm{UV} /$ vis spectrum at 335 (H-band; $\mathrm{S} 0 \rightarrow \mathrm{S} 1$ transition) and $305 \mathrm{~nm}$ (J-band; S0 $\rightarrow$ S2 transition; see Figure 1A)..$^{35,36}$ The assem$\mathrm{bly} /$ disassembly process is most conveniently followed by changes of the $305 \mathrm{~nm}$ band (Figures 1B-C; for monitoring at $260 \mathrm{~nm}$ see SI, Fig. $\mathrm{S} 11)$. Figure 1B shows the assembly of ribbons from Py-a upon cooling. The polymerization occurs via a single transition that starts at approx. $85^{\circ} \mathrm{C}$. The process is reversible, albeit some hysteresis is observed. Surprisingly, if the same procedure is performed in the presence of the complementary oligonucleotide $\mathbf{1 b}$, a second transition appears below $30^{\circ} \mathrm{C}$ (Figure 1C). The change in the intensity of the J-band reflects a conformational reorganization of the supramolecular pyrene backbone. The sharpness of this transition, characterized by the fullwidth at half-maximum (fwhm) $)^{25}$ of $1.5^{\circ} \mathrm{C}$ (melting) and $2.5^{\circ} \mathrm{C}$ (annealing), suggests a high degree of cooperativity. Also this process is reversible and shows hysteresis. In contrast, annealing/melting curves for a system containing Py-a and the non-complementary oligonucleotide 1a exhibit only a single transition below $85^{\circ} \mathrm{C}$, which coincides with the formation of Py-a nanoribbons (Figure 1D).
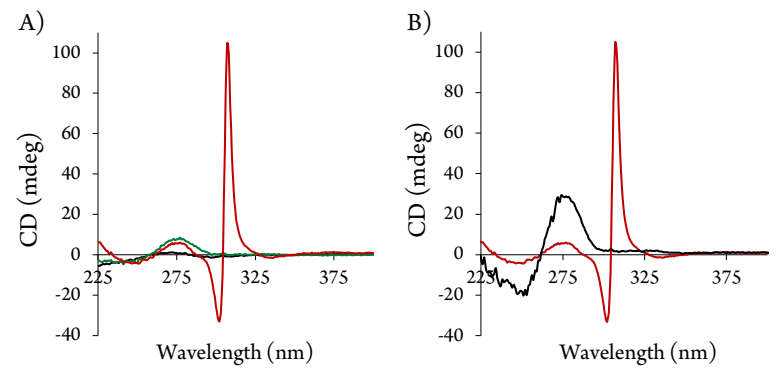

Figure 2. CD spectra at $20^{\circ} \mathrm{C}$; A) Py-a (black), Py-a $+1 \mathrm{a}$ (green), Py$\mathbf{a}^{*} 1 \mathbf{b}$ (red) prepared by slow annealing (conditions: as in Figure 1); B) Py-a* $1 \mathbf{b}$ before (red) and after (black) addition of $1 \mathrm{a}$ (conditions: as in Figure 1, except $1 \mathrm{a}$ was used at $12 \mu \mathrm{M}$ conc.).

Circular dichroism (CD) spectroscopy provides further insight in the nature of the transition observed around $30^{\circ} \mathrm{C}$. While the $\mathrm{CD}$ spectrum of the Py-a* $1 \mathrm{~b}$ system resembles the one of B-DNA below $300 \mathrm{~nm}$, it exhibits a strong exciton-coupled signal (Figure 2A, red curve ) in the $300-320 \mathrm{~nm}$ region at $20^{\circ} \mathrm{C}$. The bisignate signal $(+307 /-$ $303 \mathrm{~nm}$ ) corresponds to the J-band of assembled pyrenes. ${ }^{37 a}$ Heating to $35^{\circ} \mathrm{C}$ leads to the disappearance of the signal (see SI, Figure S2), which clearly shows that it is linked to the transition taking place in this temperature range. The appearance of the exciton coupled signal represents a change in the relative orientation of the transition dipole moments. ${ }^{37 \mathrm{~b}}$ This suggests that the stacking arrangement of the pyrenes and, hence, their electronic interaction is altered during the observed process. In contrast, the samples prepared either from Py-a alone or Py-a $+1 \mathbf{a}$ are CD silent in the $300-320 \mathrm{~nm}$ region (Figure $2 \mathrm{~A}$, black and green curves). Thus, the low temperature transition only occurs when $\mathbf{l b}$ (connector strand) is hybridized to the DNA part of Py-a.

Atomic force microscopy (AFM) was used to correlate the spectroscopic data with the morphological appearance of aggregates. Supramolecular polymers were deposited and visualized on amino-modified mica surface. Self-assembly of Py-a leads to the formation of ribbons that exhibit a length of several hundred nanometers and are randomly distributed on the surface (Figure 3A). The Py-a + 1a mixture leads to identical results (Figure $3 \mathrm{~B}$ ). In the complementary Py-a* $1 \mathrm{~b}$ system, however, polymers exist as high-density networks (Figure $3 \mathrm{C}$ ), reminiscent of haystacks in a field, rather than as individual ribbons. The formation of networks is confirmed by transmission electron microscopy (TEM; Figure S10).

The two transitions appearing in the annealing curves of Py-a in the presence of complementary oligonucleotide $1 \mathrm{~b}$ reflect the hierarchical structural organization of chimeric oligomers. Based on the combined spectroscopic and morphologic data, we propose a model for network formation as illustrated in Scheme 2. The first transition is due to the formation of nanoribbons via supramolecular polymerization of Py-a. The second cooperative transition occurs only in the presence of the complementary oligonucleotide $1 \mathrm{~b}$. DNA hybridization between $\mathbf{1 b}$ and the single-stranded oligonucleotides grafted onto the pyrene nanoribbons results in the formation of duplexes. These duplexes are arranged along the edges of the ribbons (see Scheme 2) and contain GC base pairs at their termini. Cooperative interactions between individual ribbons through coaxial stacking of these blunt-ended GC base pairs lead to network formation. We assume that each ribbon, through short patches of a few GC basepairs, is connected to neighboring ribbons; long-range collinear stacking of ribbons is unlikely. The importance of blunt end stacking interactions for the controlled assembly of DNA nanostructures and devices is well documented. 5,6,15,38${ }^{40}$ Coaxial stacking ${ }^{41-44}$ of GC base pairs is significantly stronger than of AT base pairs. ${ }^{45,46}$ This is also observed in the present case. In oligomer 1c, the two $3^{\prime}$-terminal bases are switched in comparison to $\mathbf{1 b}$ (Scheme 1). The annealing curve of oligomer Py-c in the presence of 1c shows only a single transition occurring at $80 \pm 5{ }^{\circ} \mathrm{C}$ (Figure S7). Thus, the blunt-ended AT base pairs, which are formed by hybridiza- 
tion of 1c with Py-c, do not support network formation due to decreased stability of their coaxial stacking interactions. The influence of base composition on network formation was further elicited by a series of control oligonucleotides differing in length and nucleotide sequence (see SI, Scheme S1). The data show that mismatches, overhanging nucleobases or shorter duplexes have the expected negative impact on the formation and the stability of networks. Furthermore, the hierarchical assembly is not limited to the $P y-a^{*} 1 b$ pair. Identical results are obtained with the combination Py-b*1a (SI; Figure S1), which also contains GC blunt ends.

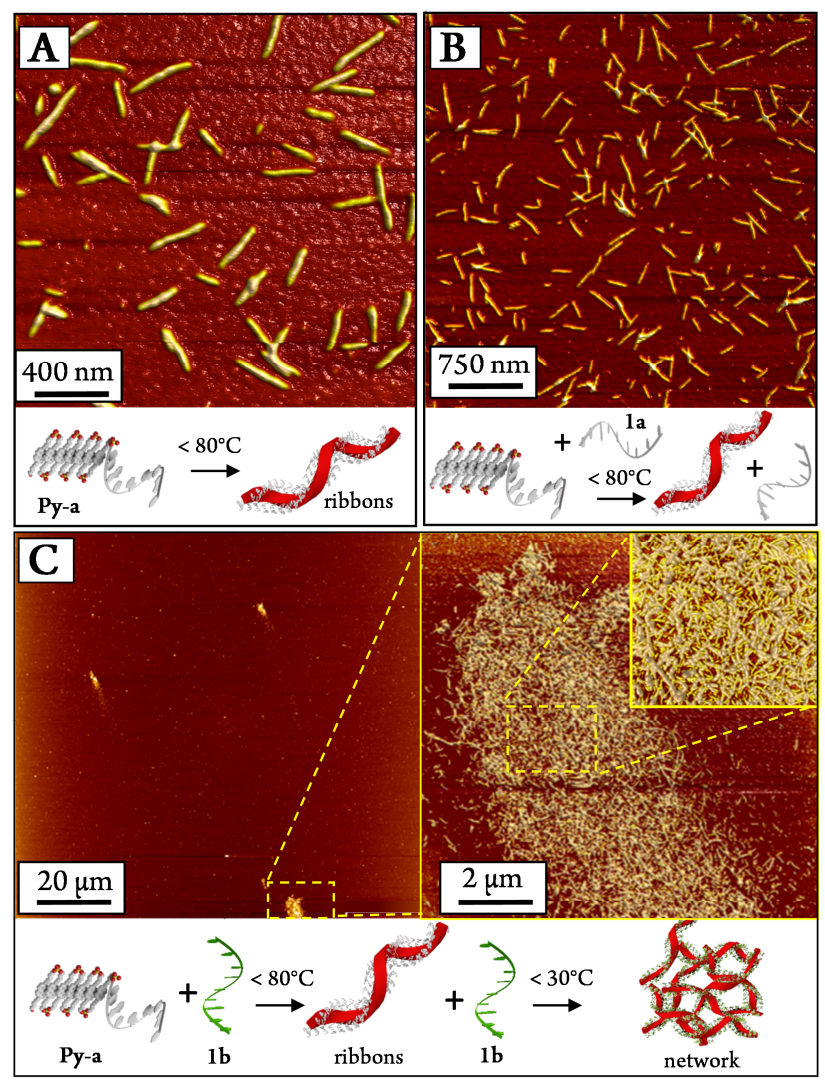

Figure 3. AFM images and illustration of supramolecular assemblies formed from Py-a (A), Py-a + 1a (B) and Py-a*1b (C). Conditions as in Figure 2.

The supramolecular nature of the interaction of nanoribbons allows reversing the network formation under isothermal condition, as shown by competition experiments. Thus, addition of the separator strand (1a, 2-fold excess over $1 \mathrm{~b}$ ) to the $\mathbf{P y}-\mathrm{a}^{*} 1 \mathrm{~b}$ network at $20^{\circ} \mathrm{C}$ results in the disassembly of the aggregates (illustrated in Scheme 2). Formation of the duplex $1 \mathrm{a}^{*} 1 \mathrm{~b}\left(\mathrm{~T}_{\mathrm{m}}=47^{\circ} \mathrm{C}\right.$, SI Figure S5) leads to the removal of the connector strand $\mathbf{1 b}$ from the network. Complete disappearance of the network is accomplished within 2 hours (SI, Figure S4C). AFM imaging shows only individual ribbons after addition of 1 a (Figure S8). The disassembly process is also confirmed by the disappearance of the $\mathrm{CD}$ signal centered around $305 \mathrm{~nm}$ (Figure 2B).

In conclusion, we have demonstrated that chimeric pyrene-DNA oligomers assemble into extended networks via hierarchical assembly pathways. The first step, self-assembly of oligomers into helical nanoribbons, is driven by aromatic stacking interactions among pyrene units. The supramolecular polymerization is independent from the nucleotide sequence of the DNA part. The second step, aggregation of individual nanoribbons into extended networks, only takes place in the presence of a complementary oligonucleotide. Hybridization leads to the formation of duplexes along the helical nanoribbon core. Coaxial stacking interactions of blunt end GC base pairs trigger the formation of a network in a highly cooperative process. The networks can be disassembled by destroying the coaxial stacking interactions either by heating or through addition of a separator strand. Supramolecular polymeric networks of this type may be relevant for the development of DNA-based smart materials, such as stimuli-responsive carriers of active ingredients.

\section{ASSOCIATED CONTENT}

\section{Supporting Information}

Additional spectroscopic (UV-vis, CD) and microscopic (AFM and TEM) data. This material is available free of charge via the Internet at http://pubs.acs.org.

\section{AUTHOR INFORMATION}

\section{Corresponding Author}

*e-mail: robert.haener@dcb.unibe.ch.

\section{ACKNOWLEDGMENT}

This work was supported by the Swiss National Foundation (Grant 200020_149148).

\section{REFERENCES}

(1) Jones, M. R.; Seeman, N. C.; Mirkin, C. A. Science 2015, 347, 1260901 .

(2) Lu, C. H.; Willner, B.; Willner, I. ACS Nano 2013, 7, 8320-8332.

(3) Zhang, F.; Nangreave, J.; Liu, Y.; Yan, H. J. Am. Chem. Soc. 2014, 136, 11198-11211.

(4) Yin, P.; Choi, H. M.; Calvert, C. R.; Pierce, N. A. Nature 2008, 451, 318-322.

(5) Woo, S.; Rothemund, P. W. Nat. Chem. 2011, 3, 620-627.

(6) Gerling, T.; Wagenbauer, K. F.; Neuner, A. M.; Dietz, H. Science 2015, 347, 1446-1452.

(7) Douglas, S. M.; Dietz, H.; Liedl, T.; Hoegberg, B.; Graf, F.; Shih, W. M. Nature 2009, 459, 414-418.

(8) Bath, J.; Turberfield, A. J. Nat. Nanotech. 2007, 2, 275-284.

(9) Nykypanchuk, D.; Maye, M. M.; van der Lelie, D.; Gang, O. Nature 2008, 451, 549-552.

(10) Ke, Y.; Ong, L. L.; Sun, W.; Song, J.; Dong, M.; Shih, W. M.; Yin, P. Nat. Chem. 2014, 6, 994-1002.

(11) Serpell, C. J.; Edwardson, T. G.; Chidchob, P.; Carneiro, K. M.; Sleiman, H. F. J. Am. Chem. Soc. 2014, 136, 15767-15774.

(12) Gong, P.; Levicky, R. Proc. Nat. Acad. Sci. (USA) 2008, 105, 53015306.

(13) Randeria, P. S.; Jones, M. R.; Kohlstedt, K. L.; Banga, R. J.; de la Cruz, M. O.; Schatz, G. C.; Mirkin, C. A. J. Am. Chem. Soc. 2015, 137, 34863489.

(14) Rafat, A. A.; Pirzer, T.; Scheible, M. B.; Kostina, A.; Simmel, F. C. Angew. Chem. Int. Ed. 2014, 53, 7665-7668.

(15) Woo, S.; Rothemund, P. W. Nat. Commun. 2014, 5, 4889.

(16) Cutler, J. I.; Auyeung, E.; Mirkin, C. A. J. Am. Chem. Soc. 2012, 134, 1376-1391.

(17) Tjong, V.; Tang, L.; Zauscher, S.; Chilkoti, A. Chem. Soc. Rev. 2014, 43, 1612-1626.

(18) Sassolas, A.; Leca-Bouvier, B. D.; Blum, L. J. Chem. Rev. 2008, 108, 109-139.

(19) Howorka, S.; Hesse, J. Soft Matter 2014, 10, 931-941.

(20) Pu, F.; Ren, J.; Qu, X. Adv. Mater. 2014, 26, 5742-5757.

(21) Kedracki, D.; Safir, I.; Gour, N.; Ngo, K. X.; Vebert-Nardin, C. Adv. Polym. Sci. 2013, 253, 115-150.

(22) Averick, S. E.; Dey, S. K.; Grahacharya, D.; Matyjaszewski, K.; Das, S. R. Angew. Chem. Int. Ed. 2014, 53, 2739-2744. 
(23) (a) Peterson, A. M.; Heemstra, J. M. WIREs Nanomed Nanobiotechnol 2015, 7, 282-297. (b) Korri-Youssoufi, H.; Garnier, F.; Srivastava, P.; Godillot, P.; Yassar, A. J. Am. Chem. Soc. 1997, 119, 7388-7389. (c) Lu, X.; Watts, E.; Jia, F.; Tan, X.; Zhang, K. J. Am. Chem. Soc. 2014, 136, 10214-10217 (d) Tan, X.; Li, B. B.; Lu, X.; Jia, F.; Santori, C.; Menon, P.; Li, H.; Zhang, B.; Zhao, J.J.; Zhang, K. J. Am. Chem. Soc. 2015, 137, 6112-6115.

(24) (a) Kwak, M.; Herrmann, A. Angew. Chem. Int. Ed. 2010, 49, 85748587. (b) Peng, L.; Wu, S.; You, M.; Han, D.; Chen, Y.; Fu, T.; Tan, W. Chem. Sci. 2013, 4, 1928-1938.

(25) (a) Watson, K. J.; Park, S.-J.; Im, J.; Nguyen, S. T.; Mirkin, C. A. J. Am. Chem. Soc. 2001, 123, 5592-5593. (b) Gibbs, J. M.; Park, S.-J.; Anderson, D. R.; Watson, K. J.; Mirkin, C. A.; Nguyen, S. T. J. Am. Chem. Soc. 2005, 127, 1170-1178. (c) Gibbs-Davis, J. M.; Schatz, G. C.; Nguyen, S. T. J. Am. Chem. Soc. 2007, 129, 15535-15540. (d) Park, S. Y.; Gibbs-Davis, J. M.; Nguyen, S. T.; Schatz, G. C. J. Phys. Chem. B 2007, 111, 8785-8791. (e) Lytton-Jean, A. K. R.; Gibbs-Davis, J. M.; Long, H.; Schatz, G. C.; Mirkin, C. A.; Nguyen, S. T. Adv. Mater: 2009, 21, 706-709.

(26) Vyborna, Y.; Vybornyi, M.; Rudnev, A. V.; Häner, R. Angew. Chem. Int. Ed. 2015, 54, 7934-7938.

(27) Häner, R.; Garo, F.; Wenger, D.; Malinovskii, V. L. J. Am. Chem. Soc. 2010, 132, 7466-7471.

(28) Aida, T.; Meijer, E.; Stupp, S. I. Science 2012, 335, 813-817.

(29) Busseron, E.; Ruff, Y.; Moulin, E.; Giuseppone, N. Nanoscale 2013, $5,7098-7140$.

(30) Yang, L.; Tan, X.; Wang, Z.; Zhang, X. Chem. Rev. 2015, 115, $7196-$ 7239

(31) van der Zwaag, D.; de Greef, T. F. A.; Meijer, E. W. Angew. Chem. Int. Ed. 2015, 54, 8334-8336.
(32) Görl, D.; Zhang, X.; Stepanenko, V.; Würthner, F. Nat. Commun. 2015, 6, 7009 .

(33) Mukhopadhyay, R. D.; Ajayaghosh, A. Science 2015, 349, 241-242.

(34) Huang, F.; Scherman, O. A. Chem. Soc. Rev. 2012, 41, 5879-5880.

(35) Vybornyi, M.; Rudnev, A. V.; Langenegger, S. M.; Wandlowski, T.; Calzaferri, G.; Häner, R. Angew. Chem. Int. Ed. 2013, 52, 11488-11493.

(36) Vybornyi, M.; Rudnev, A.; Häner, R. Chem. Mater. 2015, 27, 14261431.

(37) (a) Micali, N.; Vybornyi, M.; Mineo, P.; Khorev, O.; Häner, R.; Villari, V. Chem. Eur.J. 2015, 21, 9505-9513. (b) Pescitelli, G.; Di Bari, L.; Berova, N. Chem. Soc. Rev. 2014, 43, 5211-5233.

(38) Endo, M.; Sugita, T.; Katsuda, Y.; Hidaka, K.; Sugiyama, H. Chem. Eur.J.2010, 16, 5362-5368.

(39) Wang, R.; Kuzuya, A.; Liu, W.; Seeman, N. C. Chem. Commun. 2010, 46, 4905-4907.

(40) Nakata, M.; Zanchetta, G.; Chapman, B. D.; Jones, C. D.; Cross, J. O.; Pindak, R.; Bellini, T.; Clark, N. A. Science 2007, 318, 1276-1279.

(41) Lilley, D. M. J. Q. Rev. Biophys. 2000, 33, 109-159.

(42) Oxford Handbook of Nucleic Acid Structure; Neidle, S.; Oxford University Press: New York, 1999.

(43) Bloomfield, V. A.; Crothers, D. M.; Tinoco, I. Nucleic Acids - Structures, Properties, and Functions; University Science Books: Sausalito, 2000.

(44) SantaLucia, J.; Hicks, D. Annu. Rev. Biophys. Biomol. Struct. 2004, $33,415-440$.

(45) Saenger, W. Principles of Nucleic Acid Structure; Springer-Verlag: New York, 1984.

(46) Protozanova, E.; Yakovchuk, P.; Frank-Kamenetskii, M. D. J. Mol. Biol. 2004, 342, 775-785 


$$
\text { DE }
$$

